\title{
TECHNIQUE OF TEACHING SILENT READING
}

\author{
E. N. RHODES
}

State Normal School, Salem, Massachusetts

On January 25, 1922, the Burgess Picture Supplement Scale for Measuring Ability in Silent Reading, No. 2, was administered in the Training School of the State Normal School at Salem, Massachusetts, from Grades III to VIII inclusive. The results revealed a situation which was most unsatisfactory. The pupils throughout the school were apparently reading too slowly and certainly not with the desired accuracy.

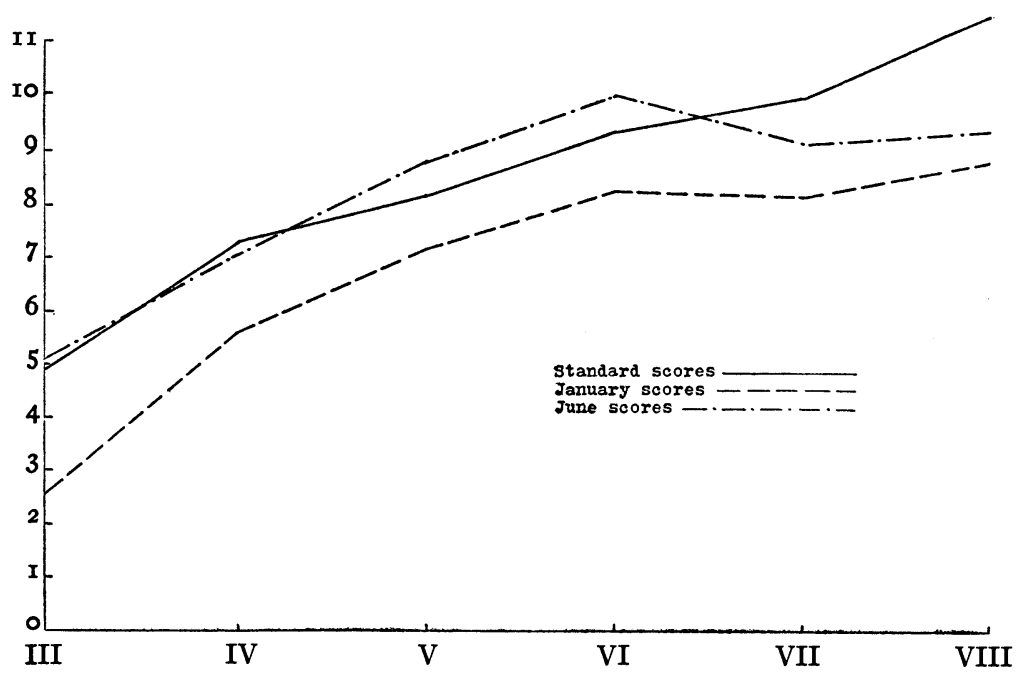

Fig. I. - Number of paragraphs correctly marked January 25 and June 5, I922

The standard scores by grades in terms of the average number of paragraphs correctly marked, the January and June scores, and the percentage of improvement are given in Table I. Figure I presents graphically the January, June, and standard scores.

It is to be noted that the January scores by grades are nearly two paragraphs below the respective grade standards. Here was 
a situation that challenged the skill of the supervisors (critic teachers). What could be done about it ? How could the pressing reading needs of several hundred children be met?

\section{TABLE I}

Average Number of Paragraphs Correctly Marked on January 25 AND JUNE 5, 1922

\begin{tabular}{|c|c|c|c|c|c|c|}
\hline & \multicolumn{6}{|c|}{ Grade } \\
\hline & III & IV & $\mathrm{V}$ & VI & VII & VIII \\
\hline $\begin{array}{l}\text { Standard scores . . . . . . } \\
\text { January scores . . . . } \\
\text { June scores. . . . . } \\
\text { Percentage of improvement }\end{array}$ & $\begin{array}{r}4.90 \\
2.54 \\
5.09 \\
100.40\end{array}$ & $\begin{array}{r}7 \cdot 31 \\
5.64 \\
7.08 \\
25.40\end{array}$ & $\begin{array}{r}8.14 \\
7.13 \\
8.79 \\
23 \cdot 30\end{array}$ & $\begin{array}{r}9.33 \\
8.25 \\
10.00 \\
21.20\end{array}$ & $\begin{array}{r}9.96 \\
8.17 \\
9.13 \\
\text { r. } .80\end{array}$ & $\begin{array}{r}\text { II.O3 } \\
8.87 \\
9.37 \\
5.60\end{array}$ \\
\hline
\end{tabular}

The writer, as director of the teacher-training department, prepared a circular for the supervisors containing such suggestions as the following:

I. Record and interpret the results of the test for each grade in accordance with the suggestions of Mrs. Burgess in "Classroom Grouping for Silent Reading Drill," Elementary School Journal, XXII (December, I92I).

a) Record individual scores on number of paragraphs tried, correctly marked, and wrong; the diagnosis of drill needed for both speed and accuracy, whether much, some, or none. Table I in the Burgess article proposes the plan.

b) Prepare a chart for each grade, analyzing the situation and pointing out specific needs to each pupil. Table III in the Burgess article gives the plan.

c) Employ a surface frequency distribution with individual names written in to show the pupil his relation to the remainder of the class.

2. Supervisors and student teachers should be in search of ways and means of improving both the speed and quality of silent reading. It is suggested that all specific points relative to experimental methods be classified as to (I) improvement of quality: (a) organization of thought, $(b)$ determination of relative values, (c) comprehension; (2) improvement of rate; (3) provision for practice.

The results of the test pointed out to the teachers the next steps to be taken in instruction. The interpretation of the significance of the results and the graphical representation of the results pointed out to the pupils their individual needs and provided the 
necessary motivation. The search for, and the discovery of, methods for teaching made it possible for the teachers to meet the needs of the pupils. The charts and tables mentioned in the Burgess article provided the basis for the division of the pupils of a grade into groups according to their needs.

It should be said that probably half of the suggestions relative to the technique of teaching silent reading which are given in this article were already in the hands of the supervisors. The writer had collected these from a great variety of sources: school surveys, circulars of city school supervisors, and various periodical references, particularly the Elementary School Journal. The writer's classes in educational measurements in connection with the study of remedial instruction, especially his summer classes of experienced teachers at the Michigan State Normal College, have added valuable contributions to the list. The suggestions of the Training School supervisors completed the list here given.

The points relative to the technique of teaching silent reading are as follows:

I. To train pupils to judge relative values.

I. Reading to find favorite verse.

2. Selecting the most beautiful descriptive scenes, the best character sketches, well-chosen and apt words and phrases, humorous passages, etc.

3. Reading to weigh the relative importance of a selection.

4. Reading the most interesting part of the story and then giving a brief synopsis of the events preceding and following the chosen incident.

5. Reading material rapidly; skimming to get a general impression of its contents in order to determine whether or not it will serve one's purpose.

6. Noting sections of material that should be read more carefully.

7. Judging the worth of material for a specific object by consulting the index and table of contents of a book.

8. When differences of opinion arise, reading to justify one's opinion; contributing to class discussion; reading aloud passages to prove points.

9. Reading the selection as a whole; determining relative value of different parts; determining relation of parts to each other and to the whole. Illustration for story reproduction: What parts must be remembered to be able to tell the story? Re-reading and observing what parts may be forgotten without destroying the story. Analyzing the selection into scenes or situations. 
II. To train pupils to find the organization of the thought of a selection and thus to discover by example how to organize their own thoughts.

I. Reading for the essential thought or essential points of the selection.

2. Making outlines of chapters.

3. Making paragraph headings; determining author's purpose.

4. Endeavoring to see whether chapters are well named and to make better headings; challenging headings.

5. Formulating questions to cover the main points.

6. Making individual reports to the class on current events.

7. Assigning special library problems.

8. Training in analyzing narrative units of different lengths.

9. When children are familiar with a subject, letting them name the items that should be included under a given heading; reading paragraphs under such a heading to discover the presence of relevant points.

Io. Dividing long stories into short stories, giving each a subtitle.

II. Reading the most interesting part of the story and then giving a brief synopsis of the events preceding and following the chosen incident.

12. Gathering sentence elements into thought units and discovering their relation to each other. Out of such practice should grow the ability and habit of skimming a page quickly and at the same time grasping the most important elements of the page. Such a habit should tend to develop speed in silent reading; in oral reading, to train the eye to run ahead of the voice and phrase words into appropriate thought groups.

13. Developing a better technique of study. Johnson ${ }^{x}$ makes the following suggestions in regard to studying and learning a lesson in history:

a) Notice the heading of the paragraph.

b) Read the paragraph.

c) Does the heading really tell what the paragraph is about?

d) Read paragraph again and find all of the different points that are mentioned. State in three or four words each of these matters and write them in your notebooks.

e) How many of them would you expect to find mentioned under this heading?

f) Point out all the matters that you would not expect to find mentioned under this heading.

g) Put them together and think of the kind of heading under which you would expect to find them all mentioned.

h) What is the subject of the chapter?

i) What things in the paragraph are directly connected with this subject?

× Henry Johnson, Teaching of History, pp.308-9. New York: Macmillan Co., r9r5. 
j) What have the other matters to do with this subject?

$k$ ) Are they necessary to give an idea of this subject?

l) What points are necessary?

$m$ ) What points, then, are most important for this subject? least important?

From the outline thus made the pupil sums up the paragraph in his own words; then, laying aside the outline, he sums up the paragraph again. Finally, the whole lesson is summed up in this manner. Emphasis is thus laid, not on the outline itself, but on the use to which it is put. The test of value is the connected account which the pupil is able to give.

These suggestions on how to study and learn a lesson in history constitute to a degree the technique of reading, and this technique should be developed in the reading class so thoroughly that it will carry over into the study of history, geography, and other content studies.

III. Comprehension.

I. Reading to find suitable story or selection to read to others.

2. Reading either individually or by groups so as to make oral or written reports to others.

3. Reading so as to draw the picture described.

4. Reading rapidly in order to answer specific questions.

5. Reading silently directions for a game, an errand, a problem, a drawing, or construction work, and then proceeding to carry them out.

6. Reading under the direction of the teacher to associate the facts of a selection with the things already known.

7. Reading a selection for purposes of dramatization.

8. Organizing competitive reading clubs.

9. Using at frequent intervals informal tests of comprehension.

Io. Improving ability to concentrate under pressure of time control.

II. Flashing questions for answers.

12. Reading for meaning rather than for word analysis and pronunciation.

13. Organizing games for drill purposes: using action cards, languageresponse cards, one-word response cards, or paragraph cards with specific questions on the back.

I4. Studying words, prefixes, suffixes, stems, and homonyms.

I5. Reading a paragraph to discover all of the different items mentioned.

16. Recognizing while reading that the material is to be used for some purpose. Expecting pupils to reproduce a selection concisely after the first reading.

17. In developing literary appreciation the power of visualization or picture-forming is most important. Selecting passages vivid in description to develop this power in pupils.

I8. Placing special stress on training which is designed to secure marked improvement in accuracy of comprehension. 
IV. Rate of reading.

r. Flashing words, phrases, or sentences; using as flash cards lines cut from old primers.

2. Organizing games; matching phrases and sentences; motivating rate in reading by the use of games.

3. Limiting the amount of time given to the readings; timing paragraph reading; frequently employing the pressure of time control; making speed a definite objective.

4. Having the teacher read a selected sentence at random and then allowing the child who first finds the place to continue.

5. Encouraging the pupil to improve his own achievement by keeping individual speed records, charts, and diagrams.

6. Training pupils to think in sentence meanings rather than in word meanings.

7. Drilling on phrases and short sentences in order to increase the span of recognition.

8. Giving phonetic drill for the recognition of unfamiliar words.

9. Training the child consciously to avoid vocalization, pointing with fingers, etc.

ro. Using informal tests for speed at frequent intervals.

II. Encouraging pupils to read three or four words at a glance; drilling on proper word-grouping to reduce number of fixations.

I2. Establishing regular, uniform, rhythmical eye-movements.

I3. Re-reading for increasing rate; checking for comprehension.

I4. Skimming, with check for comprehension.

I 5. Using care in selecting material so as to arouse interest and enthusiasm.

r6. Discovering the individual desires and interests and using them to improve the reading.

V. Provision for practice in silent reading.

I. Directing children's attention to interesting reading.

2. Arousing a desire to read by telling part of a story.

3. Encouraging the bringing in of outside reading material.

4. Giving children the opportunity to reproduce the stories read.

5. Providing lists of available and suitable library books.

6. Providing a book table in the room.

7. Encouraging the reading of supplementary material in order to solve some class problem.

8. Encouraging pupils to read for pleasure.

9. Providing children with the opportunity, under the guidance of a teacher, to browse among books in order to satisfy individual tastes; keeping a written list of books read.

ro. Rotating library books.

There is a great amount of overlapping in the preceding points, and the organization might be improved. The suggestions outlined, 
contributed as they were by a large group of people, were typed and put into the hands of the supervisors, and in this condensed form they have proved helpful.

Teachers employed such suggestions from the list as were appropriate for their respective classes. On June 5 Picture Supplement Scale, No. 3, was administered to measure the effectiveness of the methods employed. Table I shows the scores for June and their relation to the January and the standard scores. Figure I presents the results graphically. It was most gratifying to the supervisors and student teachers who were most interested in this experiment to note the improvement made. ${ }^{x}$ As one might expect, the third grade made the greatest improvement; the fourth, fifth, and sixth grades, about the same degree of improvement; and the seventh and eighth grades, the least.

Why does the curve for Grades VII and VIII take such a drop in relation to the standard and in proportion to the other grades? This question can be answered by the writer only in part. There is probably a general feeling on the part of the teachers of the two upper grades that the mechanics of reading should be acquired by the end of the sixth grade, and these phases of reading consequently are commonly neglected. During the school year in question other problems were demanding the attention of the uppergrade supervisors to the neglect of the reading situation. The curve points out very definitely that, if certain outcomes of teaching are desired, the teacher must provide special training with these outcomes in mind. If pupils can also be made conscious of the outcomes, then there is a union of forces. Certainly the results of about four months of purposeful reading work in Grades III to VI inclusive were most commendable.

The technique of teaching silent reading, even after several years of emphasis on its importance, is still far from being thoroughly worked out. If teachers in a large city system, for example, could be prevailed upon to pool their efforts on this problem by making and compiling suggestions found effective in practice, the methods of teaching silent reading could be more rapidly developed.

The exact proportion of improvement which was due to the special technique employed cannot be definitely determined since there was no control group to indicate how much improvement would have been secured without the special technique. 